\title{
Cutaneous Melanoma pTX TNM Finding v7
}

National Cancer Institute

\section{Source}

National Cancer Institute. Cutaneous Melanoma pTX TNM Finding v7. NCI Thesaurus. Code C88381.

Cutaneous melanoma in which the primary tumor cannot be assessed (e.g., curettaged or severely regressed melanoma). (from AJCC 7th Ed.) 